\title{
La derecha y el abordaje discursivo del malestar social durante el primer gobierno de Sebastián Piñera, 2010-2014
}

\author{
The Right Wing and the Discursive Treatment of Social Unrest \\ during Sebastian Piñera's First Presidential, 2010-2014
}

Carlos Durán Migliardi*

\section{RESUMEN}

Este artículo describe la forma en que la coalición de gobierno, encabezada por Sebastián Piñera durante su primer mandato (2010-2014), se dispuso discursivamente frente al significante "malestar social", en el marco de una coyuntura marcada por el inédito auge de las movilizaciones sociales y la consecuente crisis del modelo de gobernabilidad vigente en Chile desde su retorno a la democracia en 1990. Para cumplir con este objetivo, centra la atención en enunciaciones generadas por el presidente Piñera, miembros de su gabinete ministerial y autoridades de los partidos políticos de la coalición gobernante, en alusión directa o implícita al referido significante.

Como resultado de la revisión sistemática de la información disponible, se concluye que la coalición oficialista construyó, durante el periodo abordado, una interpretación específica de la noción de "malestar social", que buscaba ser coherente con la defensa de las bases del modelo económico-social característico de la sociedad chilena.
Palabras clave:

Chile, discurso político, derecha política, malestar social.

\footnotetext{
* Chileno. Doctor en Investigación en Ciencias Sociales, FLACSO México. Investigador titular, Centro de Investigación en Ciencias Sociales y Juventud CISJU, Universidad Católica Silva Henríquez, Chile. E-mail: cduranm@ucsh.cl Este artículo fue elaborado en el marco de la ejecución del Proyecto FONDECYT Regular $\mathrm{N}^{\circ}$ 1191491: “¿Hacia un nuevo campo político?: organizaciones y discursos políticos emergentes en el Chile actual (2010-2020)". El autor agradece a la Agencia Nacional de Investigación y Desarrollo de Chile, ANID, Gobierno de Chile, el financiamiento de este proyecto.
} 


\begin{abstract}
This article describes the way in which the government coalition led by Sebastian Piñera during his first term (2010-2014) discursively addressed the significant "social unrest," within the context of an unprecedented surge in social movements and the consequential crisis in the governability model in place in Chile since the return to democracy in 1990. To fulfill this objective, the author focuses his attention on the announcements made by President Piñera, members of his cabinet and leaders of the governing coalition's political parties, in direct or implicit allusion to this social unrest.

As a result of the systematic review of the information available, it is concluded that the governing coalition constructed a specific interpretation of the notion of "social unrest" during that period, which was coherent with the defense of the foundations of the traditional economic-social model of Chilean society.
\end{abstract}

Keywords: Chile, political discourse, political right, social unrest. 
Durante el año 2011 el movimiento estudiantil chileno protagonizó un intenso ciclo de movilizaciones sociales. Tanto por su extensión temporal como por el impacto político de dichas movilizaciones, existió durante años un generalizado consenso en clasificarlas como el mayor hito de protestas sociales desde mediados de la década de los ochenta del siglo pasado, cuando el ciclo contencioso antidictatorial había alcanzado su mayor expresión (Durán, 2012; Mayol y Azócar, 2011; Segovia y Gamboa, 2012). Ello, por supuesto, sin considerar los eventos producidos casi una década después cuando, en octubre de 2019, se produce la mayor dislocación del sistema político-social del Chile de los últimos 30 años. ${ }^{1}$

La conmoción generada por este ciclo de movilizaciones, que se extendió por prácticamente todo el año 2011, trascendió ampliamente el interés sectorial del mundo estudiantil universitario. Logrando instalar una impugnación a las bases mismas del modelo económicosocial chileno, sintetizada en la consigna "No al lucro", el movimiento estudiantil activó un debate hasta ese entonces neutralizado tras más de dos décadas de hegemonía del pacto de gobernabilidad postransicional, uno de cuyos ejes rectores lo constituía el consenso en torno a las bases de la revolución neoliberal llevada a cabo por la dictadura militar chilena (Moulian, 1997; Hunneus, 2014).

$\mathrm{Y}$ es precisamente en este marco que comienza a adquirir centralidad la invocación política y mediática a la noción de "malestar social", significante originariamente propio del campo intelectual de las ciencias sociales, pero que, dado el contexto acá referido, comenzó a ser invocado profusamente por los medios de comunicación, los agentes políticos y los actores sociales partícipes del conflicto estudiantil. ${ }^{2}$

Este artículo fue concluido con anterioridad al 18 de octubre del año 2019, momento en el cual las especulaciones relativas a las tendencias del proceso político chileno se vieron enfrentadas a este acontecimiento cuyo efecto dislocatorio es innegable. A partir de lo que ha sido denominado como "el estallido social", algunas tendencias que se manifestaban de modo parcial y que son abordadas en estas páginas - en especial aquellas referidas al problema del malestar social-, se aceleraron e impusieron un ritmo desbocado al proceso político chileno, alterando de modo profundo las configuraciones discursivas de sus actores.

2 Surgida originariamente de la intersección entre la psicología y la sociología, la categoría "malestar social" refiere fundamentalmente a las manifestaciones de desafección entre subjetividad individual y espacio social. Específicamente, hace referencia a 
Las crecientes referencias a la existencia de un contexto caracterizado por el malestar social contrastaban, en ese entonces, con un gobierno que parecía representar justamente aquellos valores y principios sobre los cuales se basaba el modelo económicosocial objeto del referido malestar social. Por ello es que, junto con la necesidad de hacer frente a las movilizaciones estudiantiles, conteniendo sus efectos disruptivos, bregando por recuperar el control de la agenda pública y generando instancias de negociación con las dirigencias estudiantiles y el parlamento, los actores políticos oficialistas se fueron incorporando progresivamente al debate público en torno a las razones que originaron este ciclo de protestas y a sus posibles mecanismos de salida.

Inicialmente, la disposición de los representantes del poder ejecutivo, de los dirigentes y de los parlamentarios oficialistas fue la de obviar cualquier alusión explícita al término "malestar social", optando alternativamente por causas coyunturales y políticas como explicaciones de la crisis social y política que por aquel entonces estaba aconteciendo.

Prontamente, sin embargo, comenzó a ensayarse una interpretación singular de esta noción, que buscaba conjugar el reconocimiento de un estado social crítico con la afirmación de una adhesión mayoritaria a los valores y bases de sustentación del modelo económico-social sustentado por la derecha política y económica. En otras palabras, una interpretación del "malestar social" que pudiera ser conjugada con la presencia de una adhesión sustantiva a los fundamentos éticos, culturales y sustantivos de una forma de organización social que, como la sociedad chilena, se caracterizaba en ese entonces por su fuerte orientación neoliberal.

Pues bien, el propósito de este artículo, inscrito desde el campo de la historia reciente, es justamente describir la forma en que los actores gubernamentales y oficialistas se dispusieron discursivamente

un determinado estado de desarticulación entre los valores, fines y acciones del individuo y el orden social, que producen dificultades para el desarrollo armónico de las sociedades. Sobre esto, resulta plenamente actual el texto fundacional de abordaje de esta problemática - El malestar en la cultura-, elaborado por Sigmund Freud (2016) hace ya casi un siglo. Para reflexiones actuales sobre este tópico, con relación al ámbito político, véase Córdoba (2006). 
frente a esta noción de "malestar social" durante 2011 y 2013, tiempo que media entre el inicio de las movilizaciones estudiantiles y las elecciones presidenciales con que se cierra el primer periodo presidencial de Sebastián Piñera (2010-2014). Para ello, optamos por la perspectiva del análisis del discurso político, la que asumimos como un dispositivo de abordaje textual que busca dar cuenta de la forma en que diversos eventos comunicativos permiten la producción, circulación y mutación del sentido de lo social (Renkema, 2009; Van Dijk, 2009; Laclau, 2005; Santander, 2011) en un determinado contexto sociohistórico.

De modo más específico, y entendiendo el discurso político como una de las herramientas a través de las cuales se expresa la disputa por el poder y la hegemonía en un contexto socialmente organizado, en este trabajo se interroga respecto de la existencia de un discurso específicamente referido, desde el espacio político de la derecha en el gobierno, a la cuestión del malestar social durante el contexto de emergencia de las movilizaciones sociales de 2011. ¿Es posible verificar la existencia - por parte de la derecha en el gobierno- de una voluntad de disputa por la significación de la noción de "malestar social" durante el periodo referido o, por el contrario, las referencias a dicho significante no alcanzan a conformar una unidad de sentido y corresponden, por consecuencia, a expresiones polisémicas, asistemáticas y puramente episódicas?

Para responder a estas preguntas, la estrategia de abordaje consideró, como primer paso, la reconstrucción del contexto político inmediatamente anterior a la emergencia de las movilizaciones sociales de 2011, de modo de observar los ejes discursivos que caracterizaron el despliegue del gobierno de Sebastián Piñera durante dicho periodo. Ello, con el objeto de dimensionar tanto el impacto de la irrupción de las movilizaciones estudiantiles sobre dicho despliegue, como la forma en que los actores oficialistas se dispusieron discursivamente frente a la progresiva circulación de la tesis-recurso del "malestar social”.3

Cabe señalar que nuestro abordaje de la noción de "malestar social", para efectos de este artículo, opera sobre la base de una estrategia metodológica basada en los principios de la observación de segundo orden (Luhmann, 1993), según la cual el centro de la observación no es el objeto en sí mismo (en este caso, el malestar social), sino que la 
En segundo término, se rastrearon fuentes documentales (en diversos tipos de registro y formato) del periodo 2011-2013, en las que se expusieran intervenciones referenciadas explícita o implícitamente a la noción de "malestar social", y que tuvieran la doble condición de a) ser emitidas por dirigentes políticos y gubernamentales de primera línea (presidente de la República, miembros del gabinete ministerial, dirigentes de los partidos de la coalición oficialista y parlamentarios) y b) presentar un carácter público. ${ }^{4}$

Una vez saturada la información, se ejecutó un análisis semántico de las intervenciones recogidas, con el objeto de observar la presencia en éstas de una posición discursiva en torno a la noción de "malestar social" para, por último, agrupar las intervenciones en cuatro grandes ideas-fuerza: 1) el relevamiento de la dimensión subjetiva del malestar social; 2) la descripción de un estado de empoderamiento social; 3) la detección de un problema de expectativas sociales y 4) la distinción entre derechos y deberes ciudadanos.

Como resultado de la revisión de las fuentes indicadas, se concluye que la coalición de gobierno encabezada por el presidente Sebastián Piñera, aun cuando no contaba con un relato previamente construido en torno al tópico del malestar social, elaboró una lectura coherente y unificada de sus síntomas, causas y respuestas. Con independencia de la ponderación de su fortaleza interpelativa, y sin incorporar los debates en torno a su pertinencia o valor heurístico, se expondrá la forma en que dicha lectura tuvo como aspecto distintivo el de la compatibilización entre el reconocimiento de una sensación extendida de "malestar social” con la plena vigencia y consolidación del modelo económicosocial antes que con su crisis.

forma en que dicho objeto es observado desde una determinada posición (en este caso, la posición de la derecha/oficialismo durante el periodo 2010-2014).

Expresamente, este trabajo optó por omitir aquellas reflexiones acerca del malestar social provenientes de los circuitos intelectuales de la derecha chilena. Si bien es cierto que existen fuertes conexiones entre dichos circuitos y el campo político, nuestro objetivo fue concentrar la atención en este último, habida cuenta de nuestro interés central por aquellas enunciaciones que circularon en la esfera político-pública. Reflexiones provenientes del ámbito intelectual de la derecha chilena acerca de este tópico pueden verse expuestas en Mansuy (2016), Larraín (2012) y Guzmán y Oppliger (2012). 


\section{De la "nueva forma de gobernar" a la crisis. El protagonismo del "malestar social"}

Recién cumplidas tres semanas de haber asumido su gobierno, el presidente Piñera rebosaba optimismo. A tal punto llegaba la confianza en la capacidad de su agenda programática que, en una de sus tantas apariciones públicas, declaró - haciendo alusión al ciclo de gobiernos de la Concertación- que "en 20 días yo siento que hemos avanzado más que otros, tal vez, en 20 años".

Motivos para esta licencia presidencial había muchos: hacía solo un par de meses la derecha había desalojado del ejecutivo a la Concertación de Partidos por la Democracia con un resultado electoral que, en segunda vuelta, le otorgó la mayoría absoluta de las preferencias ciudadanas; el debate público se había concentrado en el familiar terreno de la gestión y la eficiencia, y los ciudadanos se manifestaban expectantes respecto de la promesa gubernamental de despliegue de "una nueva forma de gobernar". Adicionado a ello, el terremoto y maremoto del 27 de febrero, a solo días de la asunción formal de Piñera al gobierno, había dotado de una inesperada pertinencia a sus consignas relativas al trabajo "24/7" y al "sentido de urgencia”, al mismo tiempo que neutralizado los eventuales y esperables embates opositores.

Así las cosas, y más allá de los frecuentes errores comunicacionales y denuncias de conflictos de interés de las que era objeto, durante los primeros meses posteriores a su instalación el nuevo gobierno pudo desplegar su agenda con relativa comodidad. Con una oposición aún inmovilizada por su derrota electoral, la administración piñerista supo mostrarse como expresión de una "nueva forma de gobernar", caracterizada por un "sello tecnocrático y centrado en el empresarial sentido de la eficiencia y la no deliberación política” (Durán, 2016: 197). Recurriendo a una hábil capacidad para desplazar el tradicional clivaje democracia/autoritarismo con que la Concertación había diseñado el campo de la disputa política durante dos décadas, apostaba con éxito a un dispositivo discursivo centrado en la eficiencia, la capacidad técnica y la gestación de resultados medibles y verificables. Una forma

La declaración se dio en el marco del lanzamiento de un programa de vivienda inaugurado como parte del proceso de reconstrucción post-terremoto de febrero del año 2010 (Radio Cooperativa, 4-I-2010). 
gerencial de relación con los asuntos públicos, de acuerdo con la cual, en definitiva, el destierro de los vicios de la "vieja política" - corrupción, "cuoteo político", ineficiencia- y su reemplazo por un estilo ágil, eficiente y transparente permitirían afianzar la adhesión y confianza de los ciudadanos.

El mundialmente conocido accidente y posterior rescate de los 33 trabajadores atrapados en una mina al norte del país, ocurrido hacia mediados de 2010, no hizo más que solidificar este agenciamiento discursivo. La agresiva puesta en escena de los recursos logísticos y humanos del gobierno, al igual que la eficaz alianza público-privada desplegada para cumplir el objetivo de rescatar con vida a los mineros, constituyeron un hecho político-comunicacional de profundo impacto público: el rescate de los mineros mostraba de qué forma, de acuerdo con el discurso oficial, la interacción eficiente entre el Estado y la empresa privada podía generar resultados sociales beneficiosos.

Es precisamente en este contexto que la adhesión al gobierno y a la figura de Piñera alcanzaba sus mayores niveles. ${ }^{6}$ El estilo piñerista, con su sello de eficiencia, tecnocracia y lejanía respecto de las dinámicas de deliberación política, parecía encontrar su lugar definitivo en el espacio político nacional.

A lo arriba expuesto se sumaba el estado catatónico de la oposición proveniente del mundo concertacionista: sin el control del ejecutivo, sin mayoría parlamentaria y sin un discurso político capaz de hacer frente a la coalición gobernante, la antigua Concertación no lograba agenciarse como alternativa efectiva. Un espacio político sin ideas, con un proyecto agotado y sin capacidad de respuesta frente a las iniciativas del ejecutivo, redundaba en la solidificación del liderazgo del presidente Piñera.

Y, sin embargo, hacia finales del mismo año 2010, el escenario comenzaría a cambiar dramáticamente. Los mismos estudios de opinión que medían el ascenso previo del gobierno en la valoración

\footnotetext{
6 Según la encuesta de opinión realizada mensualmente por la empresa Adimark, durante la medición de octubre del año 2010 el gobierno de Piñera alcanzó su máximo nivel de adhesión, correspondiente al $63 \%$. Otros estudios de opinión, con cifras distintas, coinciden sin embargo en identificar al año 2010 como el mejor año del gobierno de Piñera en términos de evaluación ciudadana (Adimark, octubre 2010).
} 
pública mostraban una brusca caída a solo meses del evento de los mineros. Primero como resultado de una serie de denuncias de intervención presidencial en la institucionalidad del futbol profesional, que afectaban la continuidad del exitoso director técnico de la selección chilena, el argentino Marcelo Bielsa; ${ }^{7}$ luego, como efecto de una explosiva movilización social en la austral Región de Magallanes, originada por el anuncio del fin del subsidio al precio del gas natural (Varas, 2013: 143-145).

De esta forma, a menos de un año de haber asumido, la "luna de miel” entre Piñera y la ciudadanía comenzaba a resquebrajarse. A las manifestaciones magallánicas se sumaban conflictos al interior del gobierno, que derivaron en la gestación de un primer cambio de gabinete, interpretado transversalmente como un reconocimiento de la existencia de un déficit político en un equipo cuyas competencias eran fundamentalmente técnico-empresariales. El optimismo de los primeros meses de gobierno, así, devendría en una creciente preocupación por la imposibilidad de controlar la agenda pública, por la recurrencia de los "conflictos de interés" y por la emergencia de una multiplicidad de tensiones en la gestión técnico-política del aparato gubernamental.

La primera señal de que la conflictividad social estaba trascendiendo, fue el desarrollo - entre abril y mayo de 2011 - de multitudinarias manifestaciones en oposición al Proyecto Hidroaysén, iniciativa de construcción de una central hidroeléctrica en la zona austral del país, en contra de la cual se movilizaron energías ciudadanas ampliamente trascendentes a las organizaciones ambientalistas, y que generaron un profundo impacto político y mediático, dada la inédita masividad alcanzada por una demanda usualmente concentrada en grupos de nicho.

La estrategia gubernamental frente a estas manifestaciones se centró en cuestionar su representatividad y objetar sus motivaciones

\footnotetext{
El "incidente Bielsa" acontece durante los últimos meses del año 2010. Su renuncia a la conducción de la Selección Nacional de Futbol, debido a diferencias con la dirigencia de esta actividad, derivó a un problema político generado por los conocidos intereses económicos de Piñera y su ministro del Deporte. En el rubro deportivo, la interpretación ciudadana fue que el presidente era parcial responsable de la renuncia del seleccionador, cuestión que le trajo aparejada una sensible e inmediata baja en sus niveles de adhesión y popularidad.
} 
- "políticas e ideológicas" - ocultas. Una interpretación que se sustentaba en la creencia de que la mayoría de la ciudadanía rechazaba el desorden público, valoraba la gestión gubernamental, confiaba en su eficacia para resolver los problemas públicos y valoraba más el "crecimiento económico" que la "conservación de la naturaleza".

Una posición similar fue la que asumió el oficialismo durante las primeras semanas del conflicto educacional, cuando las movilizaciones estudiantiles - que devendrían finalmente en la expresión más significativa de la protesta social de los últimos 25 años- comenzaban a despuntar, alterando progresivamente la agenda gubernamental. Una clara muestra de esta disposición inicial del gobierno, puede verse en las declaraciones del por ese entonces ministro de Educación Joaquín Lavín frente a una de las primeras marchas masivas de los estudiantes universitarios - en abril de 2011-, en las cuales apuntaba a la falta de representatividad de los manifestantes y a la inadecuación de las formas de expresión de sus demandas:

"Los que marcharon hoy no representan a todos los estudiantes, sino que a los que estudian en las universidades tradicionales, que no son más del $30 \%$ de los universitarios y que reciben los mayores recursos del Estado. El gobierno no reacciona frente a una crisis puntual ni a lo que se grita en la calle. Tenemos claro qué hacer y estamos impulsando cambios legales que permitan inyectar recursos a la educación. De hecho, la propuesta rechazada por el Consejo de Rectores incluía un plan de más de 200 millones de dólares. Las puertas de este ministerio seguirán abiertas, pero no voy a caer en la ingenuidad de abrirme a estudiar un tema cuando al día siguiente los estudiantes lo desechan y vuelven con una nueva artillería de exigencias que están totalmente fuera de mi alcance. Siempre he estado dispuesto a conversar los temas que realmente están relacionados con la educación. Lo que no se puede hacer es mezclar las legítimas demandas con exigencias políticas e ideológicas" ( $L a$ Tercera, 1-VII-2011).

La confrontación comunicacional con las movilizaciones sociales y el intento por desconocer su impacto se basaban, probablemente, en la observancia de lo que había sido el año 2010 para el gobierno: un año marcado por el éxito del clivaje político en torno a la eficiencia. Instalar al gobierno como preocupado por la gestión y la solución de 
los problemas, en oposición a grupos de estudiantes privilegiados dirigidos por "exigencias políticas e ideológicas", parecía, en principio, una posición acertada.

No obstante, la respuesta gubernamental al inicio del ciclo de movilización estudiantil generó un efecto inverso al esperado. De la misma forma como el ministro de Energía Ricardo Rainieri había enfrentado el ya referido conflicto del gas en Magallanes, advirtiendo que "el precio del gas es una fiesta que se debe terminar y que se paga caro a largo plazo" ${ }^{\prime 8}$, la reacción frente a la intensificación de las movilizaciones sociales produjo un efecto de fortalecimiento más que de disolución de su magnitud. La opción por minimizar su impacto y cuestionar su legitimidad, lejos del objetivo esperado, produjo un incremento progresivo de la adhesión ciudadana a las movilizaciones.

Así las cosas, lo que durante el primer año fue una administración sintonizada con los ejes discursivos que le habían permitido acceder al gobierno, comenzó a girar hacia un contexto de fuerte convulsión. Las movilizaciones estudiantiles alteraban no solo la agenda oficialista, sino que, además, los términos mismos en los que se daba la discusión pública, de modo tal que, ya en los primeros meses de 2011, los temas de la agenda pública eran colocados más desde "la calle" que desde el gobierno, y la inicialmente eficaz apelación a la "eficiencia", el "sentido de urgencia" y la "solvencia técnica" para resolver los problemas públicos perdía rápidamente su potencia interpelativa.

Un relato periodístico de mediados del mes de mayo (La Tercera, 22-V-2011), cuando la magnitud de las movilizaciones copaba la atención mediática y eclipsaba las iniciativas gubernamentales, sintetizaba el ánimo del entorno oficialista durante aquellas semanas:

"A medida que pasaban las horas y se acercaba la segunda cuenta de Piñera del 21 de mayo, la última sin campañas electorales de por medio, La Moneda y la Concertación se movían de acuerdo al fragor de los acontecimientos. El principal denominador común: la perplejidad. Un movimiento sin líderes visibles y al margen de la clase política se tomaba por asalto la agenda, al tocar una fibra en la

Estas declaraciones fueron formuladas por el ministro durante los primeros días del referido conflicto del gas en la Región de Magallanes. Semanas después, a mediados de enero de 2011, el ministro fue cesado de sus funciones (Radio Magallanes, 15-I-2011). 
opinión pública. El segundo piso de La Moneda trazaba teorías sociológicas para explicarlo: señalaba que HidroAysén había liberado una carga de angustia y frustraciones provocadas por la tragedia del 27-F que hasta ahora no había encontrado algo que la gatillara. Otras tesis hacían un paralelo con manifestaciones en otros lugares del mundo, como el 'Movimiento de los Indignados' en España. En ese y otros casos, como la caída de Hosni Mubarak en Egipto, fueron fenómenos que dejaron perplejos a los partidos y movimientos políticos tradicionales, y las redes sociales de internet jugaron un rol clave en la convocatoria de las protestas".

$Y$ fue en este marco en que acontece el segundo Mensaje Presidencial ante el Congreso Pleno del 21 de mayo de 2011, hito de suma significancia en la determinación gubernamental de la agenda políticoinstitucional (Durán, 2017) y oportunidad propicia para el despliegue de una estrategia de procesamiento de lo que ya, para ese entonces, era una situación de crisis para el gobierno. Pese a la fuerte expectativa generada en torno a este hito, Piñera centró su intervención en los ejes que habían definido su plataforma política de instalación, colocando énfasis en la épica de la reconstrucción, asociada al terremoto de febrero de 2010, y en el ya mencionado rescate de los 33 mineros en el norte del país. Las referencias a la contingencia social fueron mínimas, más allá de dos alusiones implícitas al clima de protesta social y a la necesidad de centrar el debate público en la producción de acuerdos:

"La educación es la madre de todas las batallas. Es la cuna de la igualdad de oportunidades. La principal vía de movilidad social. Es en la educación donde debemos ganar la batalla del futuro. Por eso, la hemos puesto en el corazón de nuestro gobierno. Pero esta lucha por la calidad y equidad de la educación no se gana con discursos o promesas. Tampoco en la calle. Se gana en la sala de clases y en los hogares.

¿Qué puede desviarnos de nuestro camino? ¿Qué puede abortar el cumplimiento de nuestra misión? Dos grandes peligros pueden impedir que lleguemos a la meta. El primero, es que el germen de la división y el virus de la beligerancia se adueñen del espacio público, y nos impidan practicar el diálogo constructivo y alcanzar acuerdos fecundos" (Cámara de Diputados de la República de Chile, 2011: s/p). 
Hacia comienzos de junio, las movilizaciones estudiantiles se habían convertido definitivamente en la mayor expresión de protesta social desde el retorno a la democracia. Resultaba a esas alturas claro que no se trataba de una espiral cualquiera, ni de que el fenómeno podía restringirse a "grupos minoritarios", intereses sectoriales específicos o efecto de situaciones puramente contingentes. ${ }^{9}$ Las sucesivas movilizaciones callejeras, la alta visibilidad pública de los voceros estudiantiles, unida a la paralización de gran parte del sistema universitario y escolar, la adhesión de una amplia porción ciudadana y la crisis de aprobación al gobierno de Piñera conformaban un cuadro que, sin espacio para la duda, podía ser caracterizado como "crítico" para las expectativas de conservación del status quo.

Y es precisamente desde esta coyuntura que el tema del malestar social comienza a instalarse ya de modo definitivo en los círculos oficialistas. A los análisis realizados por el propio ejecutivo, en los que dicho término comenzaba a aparecer con creciente recurrencia, se sumaban diversos encuentros en los que la élite política, empresarial y eclesiástica iba explicitando la interrogación sobre el origen y causas de un "malestar social", expresado no solo en las movilizaciones sociales, sino también en la reacción ciudadana frente a un conjunto de "escándalos" de irregularidades, delitos y situaciones éticamente complejas, generadas desde instituciones otrora consideradas como emblemáticas de la institucionalidad política y social del país. ${ }^{10}$

Es de esta forma como, en definitiva, lo que había sido un expectante primer año de gobierno derivó en la producción de un escenario de crisis, originado por la articulación entre la profundización de la protesta social, la disminución de la adhesión pública al gobierno

\footnotetext{
$9 \quad$ Según versiones de prensa de la época, al interior del gobierno las manifestaciones estudiantiles eran interpretadas como una mezcla entre los efectos psicosociales del terremoto y las consecuencias del cambio en la conducción gubernamental. Así, por ejemplo, y según retrataba un reportaje, el por ese entonces senador oficialista Andrés Chadwick señalaba que "Durante todos estos años hubo una masa afín a la Concertación que estuvo contenida, con dirigentes sociales que apaciguaban los ánimos para que no hubiera protestas, y que ahora ve en cualquier cosa posibilidades de manifestarse" (Qué Pasa, 19-VI-2011).

${ }_{10}$ Durante este mismo periodo se fue desplegando un conjunto de denuncias, algunas de ellas judicializadas, que afectaron a diversas instituciones empresariales y a la Iglesia católica, tales como el caso "La Polar", el caso del sacerdote Karadima, entre otros (La Tercera, 18-VI-2011).
} 
y la sensación, por parte de la elite político-social, de estar frente a un contexto inédito de impugnación y malestar ciudadano. La tesis del malestar se imponía sobre la autocomplacencia del primer año de la administración piñerista.

\section{La derecha frente al malestar social}

En gran medida debido al hecho de ser heredera política e intelectual de los valores sobre los cuales se instaló el modelo económico-social de las últimas décadas, la derecha chilena se había caracterizado por manifestar una disposición sistemáticamente distante frente a cualquier alusión a la noción de "malestar social". Su ubicación por veinte años en el ala opositora del campo político-institucional no fue argumento suficiente como para desarrollar un discurso que contuviera de alguna forma una disposición interpretativa de un eventual estado de desafección social. Muy por el contrario, su discurso se constituyó en torno a la defensa irrestricta del modelo vigente. Una defensa fundada en la interpretación de un estado de identificación social con los valores del libre emprendimiento, la competencia, la libertad individual y las oportunidades de auto-realización.

Condicionada por esta irrestricta defensa del modelo de sociedad administrado por sus adversarios políticos, la derecha construyó su lugar oposicional durante el ciclo 1990-2010, ubicándose en la posición de garante de sus fundamentos, frente a una alianza de gobierno cuyas acciones se dirigían - a juicio del discurso derechista - a deshacer sus bases de sustentación o, en su defecto, a introducir ineficiencia por medio del intervencionismo regulatorio y/o la politización de áreas en las cuales deberían primar, de acuerdo a sus convicciones, los criterios técnico-administrativos.

Una expresión clara de esta disposición discursiva lo constituyó la exitosa candidatura presidencial de Joaquín Lavín (1999-2000), un histórico dirigente de derecha reconvertido en alcalde de una de las comunas de más altos ingresos del país (Las Condes). Por medio de una eficaz estrategia político-electoral, la candidatura de Lavín se constituyó en el hito de mayor éxito en el despliegue de un discurso que, apelando a "los problemas concretos de la gente", instalaba la idea de una desafección ciudadana "con la política y los políticos". Una estrategia que ubicaba las insuficiencias y déficits de procesamiento de 
las demandas ciudadanas en la política y no en el modelo económicosocial. Un "malestar con la política", en definitiva, que inmunizaba el modelo económico-social y lo aislaba de todo cuestionamiento a sus bases ideológicas, políticas y técnicas (Durán, 2018: 8-12).

Tal fue, en términos generales, la disposición discursiva que la derecha política desplegó desde su lugar de enunciación oposicional. Fuera de ello quedaban, por consecuencia, las alusiones a factores estructurales generadores de insatisfacción que dirigieran la atención más allá de las dinámicas propias de la competencia política. A diferencia del espacio político-intelectual de la centroizquierda, que ya hacia fines de los noventa había desarrollado un amplio debate en torno al problema del "malestar social" ${ }^{11}$, la operación discursiva de la derecha lograba eficientemente encapsular sus causas a una acotada desafección con "la política", posible de resolver con eficiencia, focalización y una relación más armónica entre Estado y mercado.

El retorno de la derecha al gobierno durante 2010 y la campaña electoral que le precedió, operaron justamente en función de estos criterios: un discurso altamente tecnocratizado, en el que la oposición no era entre modelos de sociedad divergentes sino que más bien entre formas diferenciadas de "hacer las cosas": por un lado, la política, el "cálculo pequeño" y la distorsión ideológica; por el otro, la eficiencia, el primado de la técnica y la frialdad ingenieril (Varas, 2013: 17-51).

Pero los eventos de 2011, como señaláramos, deshicieron de modo abrupto la potencia interpelativa del discurso oficialista. De forma intempestiva, la irrupción del discurso estudiantil desplazó la conversación pública desde la valoración de la eficiencia hacia la pregunta

\footnotetext{
11 En el campo político-intelectual de la centroizquierda, hacia fines de la década de los 90 se abrió un amplio debate en torno a la cuestión del "malestar social", debate en gran medida activado por el Informe de desarrollo humano del PNUD, de 1998 (PNUD, 1998), que instaló el concepto. Ello derivó en la generación de dos grandes posiciones políticas al interior del mundo concertacionista - los así llamados "autocomplacientes" y "autoflagelantes"-, con diagnósticos y posicionamientos divergentes acerca del tópico del "malestar social". En los años posteriores, este concepto siguió circulando en las élites concertacionistas, siendo fuente para intensas disputas teóricas que rápidamente derivaban en diferencias políticas y estratégicas que fueron solidificando la existencia de "dos almas" divergentes al interior del mundo concertacionista. Para un tratamiento del tema, véase Menéndez-Carrión, Joignant y Garretón (1999), y Hunneus (2014).
} 
por los fundamentos del sistema económico-social chileno. Repentinamente se comenzó a hablar de "gratuidad universitaria", "nacionalización de los recursos naturales", "cambio en la estructura impositiva”, y la aparente claridad del clivaje eficiencia/ineficiencia se desplazó hacia la fractura entre una clase política que - sin distinción - representaba la defensa de un modelo desgastado e injusto, por un lado, y el malestar social representado por las movilizaciones estudiantiles, por el otro (Figueroa, 2012).

¿Cómo construir, desde el oficialismo, un marco interpretativo del malestar social que pudiera al mismo tiempo presentarse como coherente con la defensa de las bases de sustentación del modelo económico-social? ¿De qué modo construir una definición que lograra interpretar el malestar social como un fenómeno no contradictorio con la defensa de los fundamentos estructurales de un tipo de sociedad como la chilena? ¿Cómo disponerse en la disputa política frente a esta noción, sin con ello someterse al diagnóstico impugnatorio?

De la revisión de las intervenciones públicas de las autoridades gubernamentales, dirigencias de los partidos de la coalición oficialista y de sus principales vocerías, fue posible observar la progresiva conformación de un discurso acerca del malestar social, configurado en torno a cuatro ideas fuerza que, articuladas entre sí, fueron configurando un dispositivo particular, distinguible y funcional a su posición en el terreno de la disputa política de aquel contexto. En concreto, y tal como señalamos en la introducción, estas ideas-fuerza son 1) la definición del malestar en los términos de una sensación subjetiva, discordante con una realidad "objetiva" caracterizada por el crecimiento y desarrollo; 2) la visibilización de expresiones de malestar social como síntoma de una sociedad empoderada y desarrollada; 3) la generación de expectativas no plenamente satisfechas como activadora de una sensación de malestar frente al gobierno de Piñera y 4) la necesidad de afirmar el necesario vínculo entre derechos y deberes ciudadanos como condición de posibilidad para el procesamiento eficaz del malestar social.

\section{El malestar como sensación subjetiva}

Uno de los aspectos claves del debate en torno a las causas que originan el malestar social se relaciona con la pregunta acerca de su vínculo con las condiciones objetivas y/o estructurales que caracterizan a la 
sociedad en un determinado momento. $i$ Constituye el malestar social una expresión epifenoménica de condiciones materiales o, por el contrario, existe una autonomía entre ambos factores que obliga a comprenderlo con independencia al estado de cosas material u objetivo? ¿Es posible la convivencia entre un estado de bienestar objetivo y otro de malestar subjetivo?

Frente a estas preguntas, las intervenciones públicas de los actores oficialistas sostenían la existencia de una disociación entre las condiciones materiales del país - observadas en sus indicadores objetivosy las reconocidas manifestaciones de malestar subjetivo. La metáfora utilizada por el mismo presidente Piñera acerca de la distinción entre "la temperatura que muestran los termómetros y (...) la percepción térmica", en este sentido, expresaba cabalmente el despliegue de una estrategia discursiva según la cual los problemas del país no se encontraban situados en sus indicadores objetivos ni menos en las bases de su modelo de desarrollo, sino que más bien en la disociación entre estos indicadores y la sensación "subjetiva" de los chilenos. Indicios deficitarios en cuanto a felicidad o sensación de bienestar, niveles de desconfianza crecientes, déficits políticos y de comunicación, en definitiva, se expresaban en disonancia con el conjunto de indicadores relativos a crecimiento, disminución de la pobreza, dinamismo económico y políticas sociales que, a juicio de estos personeros, daban cuenta de una sociedad vigorosa. 
Tabla $\mathrm{N}^{\circ} 1$

El malestar como sensación subjetiva

\begin{tabular}{|c|c|c|}
\hline Figura & Cita & $\begin{array}{l}\text { Publicación } \\
\text { y fecha }\end{array}$ \\
\hline $\begin{array}{l}\text { Sebastián } \\
\text { Piñera, } \\
\text { presidente de } \\
\text { la República }\end{array}$ & $\begin{array}{l}\text { "Una cosa es la temperatura que muestran los } \\
\text { termómetros y otra es la percepción térmica, y yo } \\
\text { estoy seguro de que, a la larga, si la realidad va } \\
\text { por buen camino, las encuestas también van a ir } \\
\text { por buen camino". }\end{array}$ & $\begin{array}{l}\text { La Tercera, } \\
24-\mathrm{VI}-2012\end{array}$ \\
\hline $\begin{array}{l}\text { Sebastián } \\
\text { Piñera, } \\
\text { presidente de } \\
\text { la República }\end{array}$ & $\begin{array}{l}\text { Yo creo que es verdad, que hay una cierta } \\
\text { paradoja, en el sentido de que estamos } \\
\text { teniendo un crecimiento muy fuerte, pero no } \\
\text { es un crecimiento que nos haga más felices, } \\
\text { y tenemos que preguntarnos profundamente } \\
\text { por qué un país al cual le está yendo bien, } \\
\text { cuando uno recorre el mundo, acabo de estar } \\
\text { en un foro en la OCDE, con los principales } \\
\text { líderes mundiales, ninguno dejó de referirse } \\
\text { a cómo un país como Chile había enfrentado } \\
\text { un terremoto y, simultáneamente, encabezaba } \\
\text { la lista de crecimiento de los países de la } \\
\text { OCDE. Y, sin embargo, eso no nos satisface, no } \\
\text { nos hace felices. Tenemos que repensar más } \\
\text { profundamente cuáles son los verdaderos } \\
\text { objetivos del desarrollo, porque esta idea de un } \\
\text { crecimiento infeliz, o de un desarrollo infeliz, o } \\
\text { un crecimiento y desarrollo que no satisface las } \\
\text { necesidades más sentidas y más queridas de la } \\
\text { gente, es algo que nos debe hacer reflexionar." }\end{array}$ & $\begin{array}{l}\text { La Segunda, } \\
\text { 27-VII-2011 }\end{array}$ \\
\hline $\begin{array}{l}\text { Sebastián } \\
\text { Piñera, } \\
\text { presidente de } \\
\text { la República }\end{array}$ & $\begin{array}{l}\text { "Yo también creo que hay una tremenda } \\
\text { demanda, especialmente a nuestros líderes } \\
\text { políticos, de mayor diálogo, de más búsqueda } \\
\text { de acuerdos, de más cooperación, de más } \\
\text { unidad, de más confianza. Y, en consecuencia, } \\
\text { de menos descalificaciones, menos controversia, } \\
\text { menos demagogia, menos intransigencia, que } \\
\text { es lo que ha caracterizado a veces el debate } \\
\text { político de nuestro país. Y a mi juicio eso explica } \\
\text { esta demanda, en cierta forma todavía no } \\
\text { suficientemente satisfecha, explica por qué a } \\
\text { veces hay una paradoja: da la impresión que } \\
\text { vivimos en dos mundos, en dos realidades } \\
\text { totalmente distintas, que la temperatura que } \\
\text { muestran los termómetros no coincide con la } \\
\text { sensación térmica que siente la gente". }\end{array}$ & $\begin{array}{l}\text { La Segunda, } \\
\text { 27-VII-2011 }\end{array}$ \\
\hline
\end{tabular}




\begin{tabular}{|c|c|c|}
\hline $\begin{array}{l}\text { Pablo } \\
\text { Longueira, } \\
\text { ministro de } \\
\text { Economía }\end{array}$ & $\begin{array}{l}\text { "El gobierno puede exhibir parámetros en } \\
\text { todas las áreas incomparablemente mejor a los } \\
\text { gobiernos de la Concertación, pero eso no se ha } \\
\text { traducido en una valorización de la ciudadanía. } \\
\text { En parte creo que es por esta incapacidad de } \\
\text { lograr acuerdos, de continuar con ese fair play } \\
\text { que existió en la clase política y que tanto nos } \\
\text { prestigió". }\end{array}$ & $\begin{array}{l}\text { El } \\
\text { Mostrador, } \\
1-\mathrm{X}-2011\end{array}$ \\
\hline $\begin{array}{l}\text { Jaime } \\
\text { Mañalich, } \\
\text { ministro de } \\
\text { Salud }\end{array}$ & $\begin{array}{l}\text { "Estamos en presencia de una enfermedad } \\
\text { social. Tenemos un virus que es la desconfianza. } \\
\text { Y en ese sentido, creo (...) la gran enfermedad } \\
\text { que corroe nuestra sociedad y que ha tenido un } \\
\text { carácter epidémico es la desconfianza". }\end{array}$ & $\begin{array}{l}\text { El Mercurio, } \\
\text { 18-IX-2012 }\end{array}$ \\
\hline $\begin{array}{l}\text { Laurence } \\
\text { Golborne, } \\
\text { ministro } \\
\text { de Obras } \\
\text { Públicas }\end{array}$ & $\begin{array}{l}\text { "Creo que hay una desconfianza entre las } \\
\text { instituciones, en los distintos estamentos, en la } \\
\text { política, que es esencial para la democracia. Por } \\
\text { lo tanto, nosotros, como políticos - me incluyo } \\
\text { como ministro de Estado-, tenemos que dar } \\
\text { el ejemplo tratando de recuperar esa confianza } \\
\text { de la ciudadanía, y eso se logra especialmente } \\
\text { por quienes estamos integrándonos a la vida } \\
\text { política después de tantos años, que llevamos } \\
\text { poco tiempo en esto. Tenemos que dar muestras } \\
\text { claras de que se puede confiar en los servidores } \\
\text { públicos y que podemos dedicarnos a hacer el } \\
\text { bien común, más que el bien personal. Quiero } \\
\text { tratar de pregonar con el ejemplo y abocarme a } \\
\text { los temas por los cuales vine al servicio público". }\end{array}$ & $\begin{array}{l}\text { El Mercurio, } \\
\text { 18-IX-2012 }\end{array}$ \\
\hline
\end{tabular}

Fuente: Elaboración propia. Énfasis añadido.

Tal y como era expresado en las intervenciones oficialistas, esta brecha entre bienestar objetivo y malestar subjetivo presentaba causas más vinculadas a las dinámicas de la interacción entre actores políticos, y entre estos y la ciudadanía, que a condiciones materiales. La desconfianza en el trato entre los ciudadanos y entre los actores políticos, definida por el entonces ministro de Salud Jaime Mañalich como un "virus" que afectaba la estabilidad social, constituiría en este sentido una clara ilustración de esta afectación subjetiva, generadora de un malestar contrastante con la condición material de una sociedad caracterizada por la estabilidad y el progreso.

\section{El malestar como expresión de una sociedad empoderada}

Para el discurso oficialista, la aparente paradoja entre bienestar material y malestar subjetivo podía explicarse como expresión sintomática 
de una transformación sociocultural generada por el exitoso proceso de modernización de la sociedad chilena. La superación de la cultura tradicional, el acelerado acceso al consumo y el incremento de los niveles de bienestar habrían generado, de este modo, la consolidación de una sociedad más empoderada, con mayores capacidades y competencias para interpelar a sus élites y exigir un estandard mayor a su clase política.

Tabla $\mathrm{N}^{\circ} 2$

El malestar como expresión de una sociedad empoderada

\begin{tabular}{|c|c|c|}
\hline Figura & Cita & $\begin{array}{l}\text { Publicación y } \\
\text { fecha }\end{array}$ \\
\hline $\begin{array}{l}\text { Sebastián } \\
\text { Piñera, } \\
\text { presidente } \\
\text { de la } \\
\text { República }\end{array}$ & $\begin{array}{l}\text { "Siento que los ciudadanos en Chile se han } \\
\text { empoderado, tienen más conciencia de } \\
\text { sus derechos, están más exigentes, incluso } \\
\text { están muy impacientes a veces en encontrar } \\
\text { soluciones a todo, aquí y ahora. Y es bueno } \\
\text { que haya esa impaciencia y esa rebeldía, } \\
\text { pero también debemos tener una cuota de } \\
\text { realismo y de prudencia". }\end{array}$ & $\begin{array}{l}\text { Publimetro, } \\
08-\mathrm{VII}-2011\end{array}$ \\
\hline $\begin{array}{l}\text { Sebastián } \\
\text { Piñera, } \\
\text { presidente } \\
\text { de la } \\
\text { República }\end{array}$ & $\begin{array}{l}\text { "Es la ciudadanía que se expresa en las } \\
\text { protestas, en las manifestaciones, en las } \\
\text { tomas, en las huelgas de hambre. Pero no } \\
\text { solamente ahí, porque también hay una } \\
\text { mayoría de chilenos que, si bien no usa } \\
\text { esos mecanismos de expresión, también } \\
\text { quiere sentirse más empoderado, quiere } \\
\text { sentirse más escuchado, quiere sentirse más } \\
\text { protagonista". }\end{array}$ & $\begin{array}{l}\text { Radio } \\
\text { Cooperativa, } \\
\text { 26-VII-2011 }\end{array}$ \\
\hline $\begin{array}{l}\text { Sebastián } \\
\text { Piñera, } \\
\text { presidente } \\
\text { de la } \\
\text { República }\end{array}$ & $\begin{array}{l}\text { "Cuando uno analiza hoy día lo que está } \\
\text { pasando en la sociedad chilena, todos } \\
\text { estamos viendo una nueva ciudadanía, no } \\
\text { es la misma que teníamos hace muy poco } \\
\text { tiempo, hay una nueva ciudadanía, que } \\
\text { tiene mucho mayor conciencia de sus } \\
\text { derechos, que es mucho más exigente } \\
\text { con los resultados, que está mucho más } \\
\text { empoderada y que a veces también es muy } \\
\text { impaciente. Esa es la nueva ciudadanía que } \\
\text { estamos viendo". }\end{array}$ & $\begin{array}{l}\text { La Segunda, } \\
27-\mathrm{VII}-2011\end{array}$ \\
\hline
\end{tabular}




\begin{tabular}{|c|c|c|}
\hline $\begin{array}{l}\text { Sebastián } \\
\text { Piñera, } \\
\text { presidente } \\
\text { de la } \\
\text { República }\end{array}$ & $\begin{array}{l}\text { "La opinión pública es hoy día mucho más } \\
\text { exigente, s evera e impaciente en evaluar } \\
\text { y juzgar a las autoridades: presidente, } \\
\text { Congreso, partidos e instituciones". }\end{array}$ & $\begin{array}{l}\text { Soy Chile, 29- } \\
\text { I-2012 }\end{array}$ \\
\hline $\begin{array}{l}\text { Andrés } \\
\text { Allamand, } \\
\text { ministro } \\
\text { de Defensa } \\
\text { Nacional }\end{array}$ & $\begin{array}{l}\text { "(El próximo año) estará marcado por } \\
\text { una sociedad civil extremadamente } \\
\text { empoderada, redes sociales más activas } \\
\text { y potentes que nunca y, en general, el } \\
\text { clima que va a existir será de una marcada } \\
\text { exigencia a todas las autoridades". }\end{array}$ & $\begin{array}{l}\text { Las Últimas } \\
\text { Noticias, 22- } \\
\text { IV-2012 }\end{array}$ \\
\hline $\begin{array}{l}\text { Evelyn } \\
\text { Matthei, } \\
\text { candidata } \\
\text { presidencial }\end{array}$ & $\begin{array}{l}\text { "Con el progreso económico, ha emergido } \\
\text { una nueva clase media. Una clase media } \\
\text { consciente de sus derechos, consciente } \\
\text { del medio ambiente, preocupada de la } \\
\text { educación de sus hijos, que exige mejor } \\
\text { salud y que no tolera la delincuencia. Una } \\
\text { clase media que se indigna con los abusos, } \\
\text { que exige mayores oportunidades. Una } \\
\text { clase media con temor por su estabilidad y } \\
\text { por su futuro. Una clase media agobiada por } \\
\text { el sobreendeudamiento. Una clase media } \\
\text { que demanda ser escuchada". }\end{array}$ & $\begin{array}{l}\text { El Mercurio, } \\
\text { 11-VIII-2013 }\end{array}$ \\
\hline $\begin{array}{l}\text { Evelyn } \\
\text { Matthei, } \\
\text { candidata } \\
\text { presidencial }\end{array}$ & $\begin{array}{l}\text { "El malestar ciudadano es la demostración } \\
\text { más clara del progreso que hemos logrado } \\
\text { con políticas públicas serias, que entre } \\
\text { todos hemos construido". }\end{array}$ & $\begin{array}{l}\text { El Mercurio, } \\
10-\mathrm{X}-2013\end{array}$ \\
\hline
\end{tabular}

Fuente: Elaboración propia. Énfasis añadido.

Tal y como lo manifestaba la entonces candidata presidencial del oficialismo, concebir el malestar social como expresión de una sociedad empoderada permitía asumirlo como resultado del "progreso" más que de los déficits o fracasos del modelo económico-social vigente. Una interpretación funcional a la defensa y valoración de las bases de un tipo de sociedad que vería en su avance - y no en su estancamiento o decadencia- la fuente de la crítica y el malestar.

Los progresos de una sociedad regida por los principios de la autonomía y el emprendimiento individual serían, en este sentido, fuente de una progresiva dificultad en la producción de gobernanza para sociedades cada vez más complejas, cuyos miembros demandan, con creciente fuerza, mayor eficacia de la acción estatal. 


\section{3) El malestar como crisis de expectativas}

La llegada de Sebastián Piñera al gobierno en 2010 se produjo en un marco de fuerte desgaste de una coalición política que había gobernado ininterrumpidamente durante veinte años y cuatro periodos sucesivos. El énfasis en la necesidad de un nuevo impulso, un mayor vigor en la forma de gobernar y la superación de los vicios de la antigua coalición generaba, en amplios segmentos de la ciudadanía, expectativas optimistas respecto de una nueva administración, fresca, vigorosa y portadora de una "nueva forma de gobernar". La promesa de "hacer las cosas bien" y centrar la gestión gubernamental en el objetivo del crecimiento económico habría producido, así, un conjunto de expectativas referidas a la generación de cambios rotundos y manifiestos en la forma de administrar los asuntos públicos.

Un hito relevante en esta construcción del relato oficialista fue la nominación, por parte de Piñera - a pocas semanas de asumir el gobierno-, de un gabinete conformado por un significativo número de ministros independientes, venidos del mundo empresarial. Gerentes y altos cargos de empresas privadas representaban la expresión misma de un cambio en la administración gubernativa que, se suponía, pondría fin a las porosidades e ineficiencias propias de cuadros políticos, eternizados en el poder tras décadas de continuismo (Varas, 2013: 53-75).

Para el gobierno y el oficialismo, sin embargo, esta elevación en las expectativas ciudadanas generada por el cambio de administración en 2010 se tradujo en una acumulación de demandas que, al no verse satisfechas con la prontitud esperada, generaron un incremento de los niveles de malestar social y de desafección con la administración derechista. La promesa de una forma eficiente y tecnocratizada de encarar los problemas públicos se enfrentaba a una realidad mucho más compleja que la expectativa ciudadana. 
Tabla $\mathrm{N}^{\circ} 3$

El malestar como crisis de expectativas

\begin{tabular}{|c|c|c|}
\hline Figura & Cita & $\begin{array}{l}\text { Publicación } \\
\text { y fecha }\end{array}$ \\
\hline $\begin{array}{l}\text { Sebastián } \\
\text { Piñera, } \\
\text { presidente de } \\
\text { la República }\end{array}$ & $\begin{array}{l}\text { "Tratando de buena fe [de] escuchar con } \\
\text { atención lo que está diciendo la gente, no } \\
\text { solamente los que se manifiestan en las calles, } \\
\text { con las tomas, los paros, las marchas, sino } \\
\text { que también lo que está diciendo esa mayoría } \\
\text { silenciosa que se expresa de otra forma. Yo } \\
\text { creo que nos está mandando un mensaje muy } \\
\text { poderoso, nos está planteando que quieren } \\
\text { nuevas prioridades, nuevos énfasis, nuevas } \\
\text { necesidades, y también nuevas exigencias". }\end{array}$ & $\begin{array}{l}\text { La Segunda, } \\
26-\text { VI-2011 }\end{array}$ \\
\hline $\begin{array}{l}\text { Luciano } \\
\text { Cruz-Coke, } \\
\text { ministro de } \\
\text { Cultura }\end{array}$ & $\begin{array}{l}\text { "Tal vez, la crisis que hemos tenido es que } \\
\text { se apostó a que seríamos un gobierno que } \\
\text { resolvería los problemas con eficiencia, y } \\
\text { creamos un nivel de expectativas muy alto". }\end{array}$ & $\begin{array}{l}\text { El Mercurio, } \\
\text { 18-III-2012 }\end{array}$ \\
\hline $\begin{array}{l}\text { Sebastián } \\
\text { Piñera, } \\
\text { presidente de } \\
\text { la República }\end{array}$ & $\begin{array}{l}\text { "Gobernar nunca ha sido fácil y a nosotros nos } \\
\text { ha tocado particularmente difícil. El terremoto } \\
\text { de 2010, las manifestaciones, una nueva } \\
\text { ciudadanía más exigente de sus derechos e } \\
\text { impaciente frente a los resultados y la crisis } \\
\text { económica internacional, que tiene a varios } \\
\text { de los países desarrollados debatiéndose entre } \\
\text { la recesión y el estancamiento, han puesto } \\
\text { grandes dificultades en nuestro camino". }\end{array}$ & $\begin{array}{l}\text { Cámara de } \\
\text { Diputados, } \\
21-\mathrm{V}-2012\end{array}$ \\
\hline $\begin{array}{l}\text { Pablo } \\
\text { Longueira, } \\
\text { ministro de } \\
\text { economía }\end{array}$ & $\begin{array}{l}\text { "Mi visión es que ha faltado la capacidad política } \\
\text { de entender que para que un país latinoamerica- } \\
\text { no alcance el desarrollo hay un tránsito muy lar- } \\
\text { go por recorrer, y si en ese camino no se constru- } \\
\text { yen las respuestas que va exigiendo la sociedad, se } \\
\text { puede morir en el intento". }\end{array}$ & $\begin{array}{l}\text { La Tercera, } \\
24 \text {-VII-2011 }\end{array}$ \\
\hline $\begin{array}{l}\text { Sebastián } \\
\text { Piñera, } \\
\text { presidente de } \\
\text { la República }\end{array}$ & $\begin{array}{l}\text { "Vamos a enfrentar muchos obstáculos, inclu- } \\
\text { yendo trampas, cantos de sirena, caminos fáci- } \\
\text { les, demagogia, populismo e irresponsabilidad. } \\
\text { Tenemos que tener la fuerza y la visión para no } \\
\text { caer en esas tentaciones". }\end{array}$ & $\begin{array}{l}\text { El Mercurio, } \\
\text { 24-XI-2011 }\end{array}$ \\
\hline $\begin{array}{l}\text { Sebastián } \\
\text { Piñera, } \\
\text { presidente de } \\
\text { la República }\end{array}$ & $\begin{array}{l}\text { "Todos quisiéramos ir más rápido, pero no } \\
\text { podemos arriesgar un descarrilamiento, } \\
\text { como nos ha ocurrido en el pasado y les está } \\
\text { ocurriendo a tantos países más desarrollados } \\
\text { que el nuestro. El gobierno seguirá actuando } \\
\text { con responsabilidad y armonizando } \\
\text { las necesidades de la población con las } \\
\text { posibilidades de la economía. Por eso, al igual } \\
\text { que un padre de familia, como presidente } \\
\text { muchas veces debo decir que no". }\end{array}$ & $\begin{array}{l}\text { Cámara de } \\
\text { Diputados, } \\
21-\mathrm{V}-2012\end{array}$ \\
\hline
\end{tabular}

Fuente: Elaboración propia. Énfasis añadido. 
La disociación entre las expectativas de cambio - generadas por el propio discurso oficialista - y las capacidades efectivas de producción de reformas habría ido mermando, hacia el segundo año de su instalación, el apoyo ciudadano al nuevo gobierno. El malestar, así, emergía como el resultado tanto de una ciudadanía impaciente como de un gobierno que habría generado más expectativas de las que era capaz de cumplir en el corto plazo. Paradojal condición, generada tanto por las promesas de reformas del gobierno como por su "responsabilidad" para con la estabilidad económica y social del país.

\section{4) Una sociedad de derechos y deberes}

Gran parte de la energía social que conformó las movilizaciones del ciclo 2011-2012 se desplegó en función de la recomposición de un discurso ligado a la reivindicación de derechos sociales para el acceso a determinados bienes públicos, como por ejemplo el de la educación. En una sociedad caracterizada por la amplificación del rol del mercado y la reducción del Estado como agente asignador de recursos, pocos bienes públicos eran asumidos socialmente como derechos incondicionados, y más bien eran concebidos como bienes a los cuales acceder por la vía tanto del mercado como de los instrumentos focalizados y subsidiarios del Estado.

A diferencia de experiencias de movilización previas, en las que primaba el sentido corporativo de demandas de tipo sectorial, las movilizaciones sociales del ciclo referido operaron sobre la base de la reivindicación de derechos más que de la demanda por soluciones parciales. Ello implicó el ingreso a una disputa política, normativa e ideológica acerca del rol del Estado, la amplitud de los derechos sociales y el rol del mercado en la sociedad. Disputa sin lugar a duda compleja para el oficialismo que, parapetado en la dogmática defensa de un modelo centrado en el mercado, debía oficiar como agente procesador de una demanda social trascendente a sus convicciones. 
Tabla $\mathrm{N}^{\circ} 4$

Una sociedad de derechos y deberes

\begin{tabular}{|c|c|c|}
\hline Figura & Cita & $\begin{array}{l}\text { Publicación } \\
\text { y fecha }\end{array}$ \\
\hline $\begin{array}{l}\text { Sebastián } \\
\text { Piñera, } \\
\text { presidente de } \\
\text { la República }\end{array}$ & $\begin{array}{l}\text { "En las últimas semanas hemos visto } \\
\text { marchar y manifestarse a muchos escolares } \\
\text { y universitarios por una mejor educación. } \\
\text { Los hemos escuchado con mucha atención. } \\
\text { Y tienen razón. El gobierno de Chile y este } \\
\text { presidente comparten } 100 \% \text { ese objetivo. } \\
\text { Pero junto a sus derechos, los estudiantes } \\
\text { también tienen deberes: asistir a clases, } \\
\text { estudiar, y cuando se manifiesten, hacerlo en } \\
\text { forma pacífica, sin violencia ni vandalismo, y } \\
\text { respetando los derechos de los demás. Porque } \\
\text { por muy masivas que sean las manifestaciones, } \\
\text { estoy seguro que la mayoría de los estudiantes } \\
\text { quieren estudiar, los adultos trabajar, y los } \\
\text { chilenos viviry progresar en paz. Ya es tiempo de } \\
\text { terminar con las tomas y protestas, y recuperar } \\
\text { los caminos del diálogo y la propuesta". }\end{array}$ & $\begin{array}{l}\text { Las Últimas } \\
\text { Noticias, 05- } \\
\text { VII-2011 }\end{array}$ \\
\hline $\begin{array}{l}\text { Sebastián } \\
\text { Piñera, } \\
\text { presidente de } \\
\text { la República, }\end{array}$ & $\begin{array}{l}\text { "La gente no quiere antenas, no quiere } \\
\text { cárceles, no quiere cementerios, no quiere } \\
\text { generadoras de energía, no quiere basurales } \\
\text { cerca de sus hogares ni cerca de sus comunas, } \\
\text { pero todos quieren hablar por teléfono, todos } \\
\text { quieren que los delincuentes estén presos, } \\
\text { todos quieren enterrar a sus seres queridos, } \\
\text { todos quieren encender la luz y todos quieren } \\
\text { que les retiren la basura. Entonces, hay una } \\
\text { cierta contradicción entre lo que es el bien } \\
\text { particular e individual, con lo que es el bien } \\
\text { común. Y, en el fondo, es una disociación entre } \\
\text { lo que significa la libertad, que son deberes, } \\
\text { pero también significa derechos". }\end{array}$ & $\begin{array}{l}\text { La Segunda, } \\
26 \text {-VII-2011 }\end{array}$ \\
\hline $\begin{array}{l}\text { Sebastián } \\
\text { Piñera, } \\
\text { presidente de } \\
\text { la República, }\end{array}$ & $\begin{array}{l}\text { "Creo también que está surgiendo con mucha } \\
\text { fuerza, esto no se nota en las manifestaciones, } \\
\text { pero se ve cuando uno estudia profundamente } \\
\text { a nuestra ciudadanía, una mayor exigencia } \\
\text { de que la libertad, si bien significa derechos, } \\
\text { también involucra deberes. Y, por tanto, esto } \\
\text { de no desligar los derechos de los deberes, es } \\
\text { algo que también está surgiendo con mucha } \\
\text { fuerza de nuestra ciudadanía". }\end{array}$ & $\begin{array}{l}\text { La Segunda, } \\
26-\mathrm{VII}-2011\end{array}$ \\
\hline
\end{tabular}




\begin{tabular}{lll}
\hline Sebastián & "Esta sensación que se va generando en nuestro & Discursos, \\
Piñera, & país de que tenemos derecho a todo, pero no & 23-XI-2012 \\
presidente de & tenemos ninguna obligación. Tan conscientes & \\
la República & $\begin{array}{l}\text { de nuestros derechos, tan poco conscientes } \\
\text { de los derechos de los demás; tan conscientes }\end{array}$ & \\
& de las obligaciones del Estado y tan poco \\
& conscientes de las propias obligaciones. Ese es \\
& un camino que no conduce a un buen puerto. Y \\
& por eso hay que siempre recordar que detrás de \\
& cada derecho, existe siempre una obligación". \\
\hline Sebastián & "Naturalmente queda mucho por hacer. Yo Discursos, \\
Piñera, & nunca me olvido de la trampa de los países de 23-XI-2012 \\
presidente de & ingreso medio. Los países que han logrado pasar \\
la República & del subdesarrollo al desarrollo en los últimos \\
& 50 años se cuentan con los dedos de una o dos \\
& manos, la inmensa mayoría ha permanecido \\
& en su nivel de subdesarrollo y algunos pocos \\
& que han logrado ese estatus de país de ingreso \\
& medio no han podido superar esa barrera por \\
& muchas razones. En primer lugar, porque creen \\
& que llegaron a la meta antes de haber llegado y \\
& empiezan a pedir, comportarse y vivir como si \\
fueran países ricos sin todavía serlo, y se olvidan \\
que detrás de todo derecho siempre existe una \\
obligación".
\end{tabular}

Fuente: Elaboración propia. Énfasis añadido.

La resolución de esta tensión entre la necesidad de administración de una demanda social y la concesión a las reivindicaciones de los actores movilizados resultaba a todas luces compleja, como también resultaba de difícil interpretación la producción de un marco argumentativo desde el cual disputar la noción de "derechos sociales". Y es precisamente con relación a aquello que, desde el oficialismo, se elaboró el argumento de la necesidad de complementar la demanda de derechos con el reconocimiento de deberes por parte de los ciudadanos. Si los ciudadanos movilizados demandan derechos, el Estado les recuerda sus deberes para con la sociedad. Y si los ciudadanos demandas acceso a determinados bienes entendidos como derechos, el Estado les recuerda que dichos derechos deben ser expandidos en un marco de responsabilidad pública.

Esta dicotomización entre derechos/deberes permitía al oficialismo agenciarse en una posición de defensa de la estabilidad estructural, de racionalidad y de posibilismo congruente con su perfilamiento 
técnico. Frente al malestar social expresado en una mayor demanda de derechos, el oficialismo respondía desde el lugar de la racionalidad, la ponderación y la "mirada país".

\section{Conclusiones}

El malestar social constituye un significante clave de la disputa política. Su reconocimiento-desconocimiento, la interpretación de sus fuentes originarias y de sus vías de solución, al igual como la identificación política capaz de generar, son aspectos claves en las dinámicas de construcción hegemónica.

El caso chileno no ha escapado a esto. Desde fines del siglo pasado, cuando en el contexto de presentación del Informe del PNUD (1998) sobre desarrollo humano en Chile se hizo referencia al malestar social, la centro-izquierda lo acogió prontamente como un tema propio, dando paso a una extendida disputa entre distintas sensibilidades e interpretaciones respecto tanto de las causas como de las formas de procesamiento político de dicho malestar.

De parte de la derecha, la estrategia fue encapsular toda referencia al malestar al terreno político, asumiéndolo como un malestar para con "la política" y "los políticos". Una interpretación según la cual la desafección social era con la forma en que se administraban los asuntos públicos y no con el modelo económico-social ni con las bases de sustentación del tipo de sociedad emergida de la dictatura.

Paradojalmente, entonces, mientras la derecha en la oposición disociaba malestar y modelo económico-social, la centroizquierda en el gobierno tensionaba sus principios programáticos y su lugar en el aparato gubernamental, debatiendo en torno a las causas y vías de procesamiento de un malestar social cuya latencia se observaba como un problema necesario de encarar.

Pues bien, una vez instalada en el aparato gubernamental $-\mathrm{y}$ tras un breve período de estabilidad - la derecha se vio enfrentada a la en ese entonces- mayor movilización social desde el retorno a la democracia. La masividad de las manifestaciones sociales y la extendida adhesión pública a la protesta social instaló, en el corazón mismo del oficialismo, la pregunta relativa al malestar social. Exclusiva hasta entonces del campo cultural de la centro-izquierda, la necesidad por pro- 
ducir una respuesta interpretativa, política y discursiva a lo que ya se asumía inequívocamente como un malestar social se hizo imperativa en la derecha política. Ocurrió en definitiva que

"Si la derecha en el gobierno creyó más simple la tarea de gobernar, fruto de los desgastes de la propia Concertación y de sus capacidades de gestión aprendidas en el mundo empresarial, terminó por encontrarse con un malestar muy extendido que cuestiona, no slo su capacidad de administrar el Estado subsidiario sino la concepción misma de las políticas sociales de la transición, es decir, la esencia de la herencia dictatorial y concertacionista" (Boccardo y Guajardo, 2014: 8).

La emergencia del tópico del malestar al interior del gobierno piñerista condujo a un rediseño tanto de sus ejes programáticos como del equipo de gobierno, de su agenda y sus ejes discursivos. Del foco casi exclusivo en el crecimiento económico, emergieron referencias a la "desigualdad" y los "abusos", agendas programáticas de corte redistributivo y, por último, referencias discursivas al tópico del malestar social, respecto de las cuales nos hemos referido en este artículo.

Tal y como lo hemos ido exponiendo, el reconocimiento de un estado de malestar social, expresado en las manifestaciones sociales que afectaron al gobierno durante gran parte de su periodo gubernativo, presentaba el desafío de construir un relato que asociara dicho malestar a factores distintos a los del rechazo al modelo económico-social vigente en Chile. De lo que se trataba era, en definitiva, de volver compatibles la defensa de un tipo de ordenamiento social con las expresiones de malestar social hacia éste, cuestión que se tradujo en un relato cuyos componentes nos propusimos describir en este artículo.

Sin embargo, y pese a este intento de traducción política de un estado social de malestar expresado durante el primer gobierno de Piñera, su segundo mandato debió enfrentar lo que sin dudas constituyó hasta ese entonces la mayor expresión de crisis del sistema político emergido en Chile desde el retorno a la democracia en 1990. Nuevamente, y como si las operaciones discursivas ensayadas en el periodo anterior no hubieran tenido utilidad alguna, el significante "malestar social" volvió a anteponerse a la agenda política de una administración que debió observar cómo la conmoción del año 2011 no 
fue sino, en vista a los hechos actuales, el prolegómeno de la dislocación del año 2019.

\section{Referencias bibliográficas}

Fuentes primarias

\section{a) Publicaciones oficiales}

Cámara de Diputados de la República de Chile (2011). Mensaje Presidencial, recuperado de: https://www.camara.cl/camara/ media/docs/discursos/21mayo_2011.pdf, revisado el 13-II2017.

Programa de las Naciones unidas para el Desarrollo PNUD (1998). Desarrollo humano en Chile 1998. Las paradojas de la modernización. Santiago de Chile: PNUD.

b) Publicaciones periódicas

El Mercurio, Santiago, 2011-2013.

El Mostrador, Santiago, 2011-2013.

La Tercera, Santiago, 2011-2013.

Las Últimas Noticias, Santiago, 2011-2013.

Publimetro, Santiago, 2011-2013.

Qué Pasa, Santiago, 2011-2013.

Radio Cooperativa, Santiago, 2010-2014.

Radio Magallanes, Punta Arenas, 2011-2013.

Soy Chile, Santiago, 2011-2013.

\section{Fuentes secundarias}

a) Artículos y capítulos de libros

Bocardo, G. y F. Guajardo. (2014). “ ¿El ocaso de la política de la transición?", en Cuadernos de coyuntura nodo XXI, vol. 2, N 2, pp. 5-16.

Córdova, M. (2006). “Democracia, gobernabilidad y malestar social en América Latina. Una reflexión", en Revista mexicana de ciencias politicas y sociales, vol. 48, $\mathrm{N}^{\circ} 196$, pp. 93-111.

Durán, C. (2018). "Campo político-institucional y procesamiento del malestar social en Chile, 1999-2009", en Izquierdas, $\mathrm{N}^{\circ} 40$, pp. 1-32. 
Durán, C. (2017). "Significaciones de la democracia en los mensajes presidenciales chilenos: 1990-2014", en Cuhso, vol. 27, № 2, pp. 37-68.

Durán, C. (2016). "Chile vuelve al vecindario: de la complacencia al malestar", en Caldera, A. y A. Chaguaceda (coordinadores). Democracia en América Latina: entre el ideal utópico y las realidades políticas. México D.F., Fontamara, pp. 187-209.

Durán, C. (2012). "El acontecimiento estudiantil y el viraje del proceso sociopolítico chileno", en Observatorio Social de América Latina, $\mathrm{N}^{\circ} 31$, pp. 39-60.

Luhmann, N. (1993). "Deconstruction as Second-Order Observing", en New Literary History, № 24, pp. 763-782.

Mayol, A. y C. Azócar. (2011) "Politización del malestar, movilización social y transformación ideológica: el caso 'Chile 2011', en Polis, vol. 10, ํㅜ 30, pp. 163-184.

Santander, P. (2011). "Por qué y cómo hacer Análisis de Discurso", en Cinta de Moebio, $\mathrm{N}^{\circ}$ 41, pp. 207-224.

Segovia, C. y R. Gamboa (2012). "Chile: el año que salimos a la calle", en Revista de Ciencia Política, vol. 32, N 1, pp. 65-85.

b) Libros

Figueroa, F. (2012). Llegamos para quedarnos. Crónicas de la revuelta estudiantil. Santiago de Chile: LOM.

Freud, S. (2016). El malestar en la cultura. Madrid: Alianza.

Guzmán, E. y M. Oppliger. (2012). El malestar de Chile ¿Teoría o diagnóstico? Santiago de Chile: Ril Editores.

Hunneus, C. (2014). La democracia semi-soberana. Chile después de Pinochet. Santiago de Chile: Taurus.

Laclau, E. (2005). La razón populista. Buenos Aires: Fondo de Cultura Económica.

Larrraín, L. (2012). El regreso del modelo. Santiago de Chile: Libertad y Desarrollo.

Mansuy, D. (2016). Nos fuimos quedando en silencio. La agonía de la transición chilena. Santiago de Chile: Ediciones IES.

Menéndez-Carrión, A., A. Joignant y M. A. Garretón. (1999). La caja de pandora. El retorno de la transición chilena. Santiago de Chile: Planeta-Ariel. 
Moulian, T. (1997). Chile Actual. Anatomía de un mito. Santiago de Chile: ARCIS-LOM.

Renkema, J. (2009). Introducción a los estudios sobre el discurso. Barcelona: Gedisa.

Van Dijk, T. (2009). Discurso y poder. Barcelona: Gedisa.

Varas, A. (2013). El gobierno de Piñera (2010-2014). La fronda aristocrática rediviva. Santiago de Chile: Catalonia.

c) Sitios web

Adimark, www.gfk.com/es-cl, revisado el 15-II-2017

Piñera Echeñique, S. (2010-2015), Discursos, http://www.sebastianpinera.cl/discursos, revisado el 30-XI-2019. 